\title{
EL GOBIERNO CORPORATIVO COMO INSUMO PARA UNA BUENA REPUTACIÓN CORPORATIVA
}

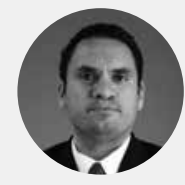

\author{
JUAN A. ARBULÚ \\ - Consultor \\ Programa de Gobierno Corporativo \\ International Finance Corporation (IFC) - World Bank Group
}

\section{RESUMEN}

Este ensayo busca definir los conceptos de reputación corporativa, gobierno corporativo y gestión de riesgos en una institución. La reputación corporativa es de vital importancia para las empresas. Ella puede entenderse como la imagen proyectada ante los distintos grupos de interés. El gobierno corporativo surge de la necesidad de dar respuesta a las dificultades de gestión y actuaciones poco éticas que afectan la imagen empresarial y con ello la rentabilidad de las organizaciones. Por tanto, un gobierno corporativo será indispensable para la reputación corporativa, en cuanto representa una oportunidad de analizar los valores y procesos que conlleven a una mejor valoración e imagen de la empresa, todo ello de la mano de un trato justo y equitativo. En todo negocio se presentan riesgos de diferente tipo y efecto. Es fundamental, por ende, el manejo eficiente de los diferentes riesgos que afronta una organización, desde su identificación, disminución de sus efectos, hasta su aceptación. El directorio es la instancia encargada de definir una cultura organizacional, enfocada en la gestión de riesgos. Y en esta línea, este ensayo subraya la relevancia del riesgo "reputacional". Si este riesgo es manejado incorrectamente, se tendrá un resultado negativo en la reputación corporativa.

Palabras clave: reputación corporativa, gobierno corporativo, gestión de riesgos.

\footnotetext{
ABSTRACT

This essay seeks to define the concepts of corporate reputation, corporate governance and risk management in an institution. Corporate reputation is of vital importance for companies; it can be understood as the image projected to different stakeholders. Corporate governance arises from the need to respond to management difficulties and unethical actions affecting the image and, thus, the profitability of an organization. Therefore, corporate governance will be indispensable for corporate reputation, as it represents an opportunity to analyze values and processes that lead to a better company valuation and image, all of this alongside a fair and equitable treatment. In every business there will be risks of different type and effect. Efficient risk management is, therefore, fundamental. This ranges
}

from its identification and acceptance, to the reduction and control of its effects. The board of directors is in charge of defining an organizational culture focused on risk management. Accordingly, this essay stresses the relevance of "reputational" risk. If this risk is incorrectly handled, a negative result as to corporate reputation would be observed.

Keywords: corporate reputation, corporate governance, risk management.

\section{I. ¿QUÉ ES LA REPUTACIÓN CORPORATIVA? ¿Y LA ÉTICA EN LOS NEGOCIOS?}

No hace falta tratar de explicar la crisis en la que nuestra sociedad se encuentra ni tampoco hacer mayor análisis para entender que estamos ante una enfermedad endémica que ataca a la familia como núcleo formador; a la persona como compuesto de conciencia y virtudes, a la convivencia y la confianza, a la responsabilidad frente a los demás; al respeto y a la vergüenza propia; en sí, a la propia acepción que le damos cada persona a la ética, a la moral y al temor; que se modifican y reconstruyen según la conveniencia, ya no de la persona misma, sino del momento, hasta en ser inconsecuente. No se es hoy en día consecuente, incluso, en los propios conceptos de inmoralidad e ilegalidad.

Muchos años, esfuerzo y dedicación hacen falta para construir una imagen positiva sólida, real y con cimientos fuertes; y basta con una sola inconducta para que esta imagen caiga y haga caer consigo resultados económicos $\mathrm{y}$, a veces, hasta la propia existencia de una empresa. Ahora, también es cierto que ha habido comportamientos reprochables en gestores o directores que no han originado desmedro alguno en la buena imagen de la compañía o una crisis en su rendimiento o valor.

Cada vez más, los bienes o activos no tangibles asumen un alto valor dentro de las compañías, muchas veces cuantificables, otras, si no son medibles en forma directa, lo son por los efectos o las consecuencias que su afectación pueden originar.

Tiempo atrás, el principal objetivo de las empresas era la rentabilidad por encima de cualquier otro riesgo. Como señala Costa (1977), la imagen era algo "apenas significativo frente a lo que era consustancial con las finalidades productoras y económicas de las empresas, 
que no eran desde luego las de cultivar una buena imagen, sino las de fabricar y vender cada vez más al mayor número posible de clientes" (p. 26).

Ha señalado Wartick (2002) que la reputación corporativa es la "agregación de las percepciones de cada uno de los participantes sobre cómo la organización responde y satisface las demandas y expectativas de los stakeholders de la organización" (p. 371).

Por su parte, Villafañe (2002) la define como el "Reconocimiento que los stakeholders de una organización hacen de su comportamiento corporativo a partir del grado del cumplimiento de sus compromisos con relación a sus clientes, empleados, accionistas y la comunidad en general" (p. 24).

En el concepto dado por el Foro de Reputación Corporativa y el Reputation Institute, la "Reputación Corporativa" es el conjunto de percepciones que tienen sobre la empresa los diversos stakeholders con los que se relaciona, tanto internos, como externos, como resultado del comportamiento desarrollado por la empresa a lo largo del tiempo y de su capacidad para distribuir valor entre los mencionados grupos.

La Real Academia de la Lengua Española concibe la reputación como: 1. Opinión o consideración en que se tiene a alguien o algo; 2. Prestigio o estima en que son tenidos alguien o algo.

Entonces, este concepto siempre estará relacionado con dos aspectos: cómo se muestra la empresa hacia fuera y cómo es concebida la empresa desde fuera, con la particularidad que le imprima cada stakeholder.

En ese sentido, podríamos entonces concluir una definición propia de reputación corporativa, entendida como "aquella imagen de aceptación que los distintos stakeholders se formen a partir del comportamiento de una sociedad".

Por consiguiente, la reputación vendrá siempre dada por la proyección que la constitución, estructura, acciones y resultados que la empresa emita frente a sus grupos de interés, la sociedad y el mercado mismo, que le responderán con confianza, relaciones comerciales, referencias de negocio, etc.

Un concepto recurrente en toda definición y que considero necesario aclarar es el de stakeholder o grupo de interés. La referencia más fuerte al término es sin duda, Edward Freeman. Es quien lo ha acuñado y le ha dado presencia en el mundo de la planificación, la ética empresarial y el management. Sin embargo, a la vez, es el mismo Freeman quien ha ido moldeando, modificando el término a lo largo del tiempo; y no está dado por la fragilidad o inexactitud original del mismo, sino porque al ser las sociedades, las relaciones comerciales y la realidad tan cambiantes, este concepto no ha estado exento de críticas y actualizaciones, ya que es un término necesario e importante en el desarrollo empresarial.

En una de sus últimas definiciones, Freeman (2010) concibe a los stakeholders como "aquellos grupos que pueden afectar o ser afectados por el logro de los propósitos de la organización", pero reconoce que pueden haber varios tipos de ellos. Los primarios, por ejemplo, ejercen una influencia directa en la organización y vital para su crecimiento y permanencia. Los instrumentales, por su lado, son aquellos que están alrededor de los primarios, influenciándolos.

Una buena reputación corporativa comporta una serie de beneficios palpables, como son la mejora en los resultados económicos, el aumento de su valor comercial. Representa un fuerte respaldo contra la crisis, pues una buena reputación generará confianza a pesar de las dificultades. En definitiva, la buena reputación corporativa está íntegramente relacionada con el concepto de liderazgo. Instituye una nueva noción de liderazgo, que requiere condiciones más exigentes que los resultados numéricos. Hay diversos estudios y escritos, por ejemplo, que hablan de la relación muy directa que existe entre la buena reputación y el valor bursátil de una empresa.

Como ya lo hemos señalado, consecuencias negativas en este aspecto son el resultado de una evidente crisis de valores, que debería estar presente en la confianza que debe generar la palabra y el compromiso.

Hablar de valores implica tener a la mano numerosas acepciones, unas más enraizadas que otras. Filosóficamente estamos frente a la estimación, cuantificación que puede hacerse de diferentes bienes, realidades, según las bondades o características que puedan tener. Si lo tomamos desde una perspectiva ética, estos son entendidos como preceptos, principios que marcan la línea de acción y conducta de una persona, organización o grupo; aunque siempre estarán encasillados en un individuo.

Ahora, como señalan Díaz, Gutiérrez y Vásquez (2007):

Una cuestión fundamental que se ha de determinar con carácter previo es qué se entiende por comportamiento ético. Desde una postura tomista, implica una actuación conforme a la naturaleza humana según el querer original de Dios. Para el agnóstico habría que decir, sin embargo, una actuación conforme la naturaleza del hombre, según la concepción naturalista aristotélica y de acuerdo con lo estudiado en las facultades de derecho como derecho natural: es decir un conjunto de normas jurídicas universales e inmutables. No obstante hay quienes ponen en duda la existencia de una serie de virtudes aceptadas por todos como esenciales a la naturaleza humana y niegan la existencia de un derecho natural. Para acudir a unos valores establecidos y aceptados universalmente quizás lo más seguro sea la Declaración Universal de Derechos Humanos, el único punto de partida donde podríamos hablar de absoluta y general aceptación. (p.29)

El Bloque 3 de la Declaración, sobre los valores éticos, el Derecho y la Propia Declaración (DUDH), del Código Ético de la Declaración Universal de los Derechos Humanos, entendido como una compilación de las normas y reglas que determinan el comportamiento ideal o más apropiado para las personas, establece cuáles son las prácticas y acciones que una persona debe realizar cuando forma parte de un grupo. Los códigos éticos se aplican a un grupo de personas que forman una asociación, partido político o agrupaciones de profesionales. 
Señala el Código que sus reglas pueden estar escritas o ser implícitas, es decir, se conocen, pero no están registradas. La ética va más allá de las leyes vigentes en un país. Algunas actividades pueden considerarse como legales pero no éticas. Puede ser legal que un político acepte regalos o privilegios por su condición, aunque la ley no lo prohíba, sin embargo, no es ético porque se produce un trato de favor. Por tanto, el hecho de actuar conforme a la ley y a los reglamentos establecidos es sólo una parte del comportamiento ético. La ética es superior y más trascendente que la legalidad en el plano del respeto a los derechos humanos de igualdad, dignidad o respeto, por ejemplo. Las leyes que se fundamentan en el Derecho permiten las relaciones entre los individuos de una sociedad; y tienen una dimensión normativa, siendo su origen el concepto griego denominado nomos, que hace referencia a: a) Las opiniones o creencias colectivas sobre lo que es mejor para el ser humano; b) las costumbres sociales en la medida en que son normas no escritas pero mantenidas; c) la ley--el conjunto de leyes por las que se rige una comunidad.

Pero las leyes deben tener también una dimensión ética o de mejora, que expresen el ideal de una sociedad más justa. Una expresión de este ideal de sociedad más justa la encontramos en la DUDH. La DUDH, continúa diciendo el Código; constituye un código ético reconocido por los países integrantes de la ONU. Los valores en los que se sustenta dicha declaración son: la justicia, la igualdad, la dignidad, el respeto y la integridad personal. La protección de los derechos humanos y las libertades fundamentales constituye una cuestión esencialmente internacional en la DUDH y como código ético fundamental, se fundamenta en el reconocimiento del ser humano como persona poseedora de unos derechos universales inalienables e innatos, tal y como se expresa en su preámbulo. Asimismo, los derechos expresados en la Declaración son derechos naturales, inherentes a la naturaleza humana; son inviolables (i.e., nadie los debe violar); son inalienables (i.e., propios del individuo); son universales (i.e., afectan a todas las personas sin excepción); son imprescriptibles (i.e., indefinidos en el tiempo); y son también indivisibles e interdependientes (i.e., no se pueden dividir o separar del individuo).

Ahora, introducir el concepto de ética y moral en los negocios, conlleva a una reflexión previa de si se trata de conceptos ambiguos, antagónicos e irreconciliables, dada la cultura generalizada de desconfianza en el empresario, a quien se le concibe como alguien dispuesto a lograr éxito empresarial sin importar los medios, que pueden estar dados por conductas poco éticas y responsables. Pasando por concepciones como las de Friedman quien ha defendido que la única responsabilidad social que debe tener una empresa es la concentrada en sus propietarios, lejano de toda responsabilidad social corporativa, hasta Galbraith quien concibe la publicidad ligada a los negocios como un objetivo de generar necesidades en el público, que antes no tenía, es decir, una gestión poco ética en sí misma. Sin embargo, ya prevalece en el presente una tendencia social de los negocios, desde su existencia misma hasta la generación de beneficios comunes en la sociedad, generación de empleo, enriquecimiento masivo e impuestos.

Como señala Cortina Orts ${ }^{1}$,

La ética de los negocios surge en cierto sentido como una revolución, puesto que es la respuesta a una demanda social, de los ciudadanos, no de los dirigentes. Sin embargo, en la empresa, al igual que en cualquier otra organización, la única forma posible de que los valores sean compartidos y se institucionalicen, es cuando existen líderes que determinen los valores y comportamiento de toda la organización. De ahí que resulte fundamental el compromiso de los ejecutivos para que la empresa y los negocios tengan en cuenta los valores éticos, para que éstos constituyan el carácter de la empresa. De esta forma, será factible que todos los miembros de la organización puedan actuar éticamente, sin necesidad de tener que asumir el papel de héroes.

En esta ponencia expone cuáles son a su concepto, las cinco razones de propugnar y luchar por la incorporación de la ética en distintas ramas. Las mismas son: el fin de las ideologías; la necesidad de que exista confianza para el buen funcionamiento de la economía; las buenas prácticas empresariales; la idea de que la ética es rentable, y la existencia de una ética cívica compartida por todos los ciudadanos.

Por su parte, Díaz et al. (2007):

Afortunadamente, hoy en día, la ética interesa no sólo a los filósofos, sino también a los economistas, a los juristas y a los consumidores, lo que implica la aceptación de la idea de que si bien la finalidad de los negocios es el lucro no es incompatible con una regulación de la actividad en el mercado que evite comportamientos no éticos. Y esto es así, porque la ética es rentable para las empresas. No nos referimos a que invertir en negocios éticos produzca más beneficios. De hecho han existido y existen fondos de inversión que, por razones éticas, excluían de sus inversiones a negocios o empresas determinadas, y no demostraron que su rentabilidad fuera superior al resto de fondos. Desde luego, tiene lógica pensar que cuando una empresa lleva una política empresarial ética su gestión será buena y, consiguientemente, las probabilidades de que el valor de sus acciones caigan en forma significativa, por pérdida de reputación, o toma de decisiones empresariales equivocadas, son mucho menores (...) En la actualidad la rentabilidad de la empresa ética radica en la confianza que genera. Tanto en el ámbito interno de la empresa, es decir, sus trabajadores son más conscientes de estar realizando una labor positiva para la comunidad, contribuyendo a su progreso y bienestar; como para los consumidores, o si se prefiere, desde un punto de vista más mercantilista, para los clientes, cuyo número potencial aumenta de esta forma (...)

1. Ver Cortina Orts, A. Hacia una nueva cultura empresarial (1994-2005), en XV Seminario Permanente de ética Económica y Empresarial (2004-2005), Ética de la Empresa: Hacia un Nuevo Orden Global, Valencia, Fundación Etnor, pp. 7-19. 
La ética de los negocios debe ser una ética de las personas, porque, como decíamos, al fin y al cabo, los comportamientos éticos dependen de las personas. Pero tales comportamientos deben transmitirse e imbuir en las organizaciones. Debe, por otra parte, estar enfocada hacia resultados palpables, pues de lo contrario estaríamos ante un conjunto de grandes y buenas ideas, pero etéreas y sin funcionalidad alguna. No obstante, no debe centrarse únicamente en el resultado, sino que para que sea una actuación permanente, una manera de entender las actividades que los diferentes agentes económicos realizan en el mercado, debe estar basada en el convencimiento. Y, por último, tiene que tener en cuenta a todos los afectados por la actividad económica. (pp. 34 - 35)

\section{ASPECTOS RELEVANTES DEL GOBIERNO CORPORATIVO QUE INFLUYEN EN LA BUENA IMAGEN DE LA EMPRESA}

Todos los que estamos de una u otra manera involucrados en el Gobierno Corporativo (en adelante GC), sabemos que no existe una definición exacta para esta área de estudio y gestión. Sin embargo, entendemos de su necesidad para que las empresas o entidades que lo aplican definan su rumbo. Como se señala en el discurso ${ }^{2}$ a raíz de la aceptación de la revisión del año 2004 de los Principios de Gobierno Corporativo de la Organización para la Cooperación y el Desarrollo Económico (OECD, por sus siglas en inglés), el GC trata de la forma en que las juntas directivas supervisan el funcionamiento de una empresa por parte de sus gerentes y cómo los miembros de la junta son a su vez responsables ante los accionistas y la compañía. Esto tiene efectos para el comportamiento de la empresa hacia empleados, accionistas, clientes y bancos. El buen GC, señala el documento, juega un papel vital en apuntalar la integridad y la eficiencia de los mercados financieros. El mal gobierno corporativo debilita el potencial de una empresa y, aún peor, puede allanar el camino para las dificultades financieras e incluso el fraude. Si las empresas están bien gobernadas, generalmente superarán a otras compañías y podrán atraer inversores cuyo apoyo puede ayudar a financiar un mayor crecimiento.

Según el Informe del Comité de Gobierno Corporativo de la Bolsa de Valores de Toronto, en Canadá, del año 1994, el GC significa el proceso y la estructura utilizados para dirigir y administrar los negocios de la empresa con el objetivo de mejorar el valor para los accionistas, lo cual incluye garantizar la viabilidad financiera del negocio. El proceso y la estructura definen la división de poderes y establecen mecanismos para lograr la rendición de cuentas entre los accionistas, la junta directiva y la administración. La dirección y administración del negocio, señala, deben tener en cuenta el impacto sobre otras partes interesadas tales como empleados, clientes, proveedores y comunidades.

2. Ver http://www.oecd.org/corporate ca/corporategovernanceprinciples/ improvingbusinessbehaviourwhyweneedcorporategovernance. htm
Por su parte, la International Finance Corporation (IFC) ${ }^{3}$ ha señalado ${ }^{4}$ que el gobierno corporativo puede significar muchas cosas diferentes. Una definición útil es que el gobierno corporativo establece estructuras claras de rendición de cuentas, responsabilidad y transparencia al mando de la empresa y define el papel de la junta y la administración. Esto significa que con un buen gobierno corporativo se establecen los controles y equilibrios adecuados entre la gerencia y los propietarios (y posiblemente otros interesados, como los empleados); los flujos de información y los informes son claros y transparentes; se ha generado responsabilidad entre las diferentes capas de la organización; se establecen controles internos y prácticas de gestión de riesgos; $\mathrm{y}$ los altos estándares éticos se convierten en la norma en toda la compañía. Con respecto a la gestión de crisis, el buen gobierno corporativo permite que la junta directiva y la alta gerencia capturen los problemas que surjan y eviten que se conviertan en una crisis o un desastre. Y si surge un problema a pesar del buen gobierno corporativo (por ejemplo, de factores externos), las funciones y responsabilidades de los diferentes tomadores de decisiones son claras; los órganos corporativos y los funcionarios saben qué hacer; las contingencias se discuten abiertamente; y las soluciones se pueden encontrar rápidamente. ${ }^{5}$

El nacimiento o surgimiento del GC no puede atribuirse a un pensamiento, a un hecho aislado o a un evento que lo tuvo necesariamente como objetivo. Debe atribuírsele, más bien, sino a una serie de hechos que generaron un panorama en el cual se necesitaba de la reorganización de estructuras, ideas, formas de gestión y de asumir mayores responsabilidades a la hora de gestionar una empresa y medir el impacto de sus decisiones. En ese sentido, catástrofes empresariales que originaron el mayor colapso bursátil que se haya podido presentar en Estados Unidos, como Enron, Worldcom, Global Crossing y Arthur Andersen, tienen su origen en desórdenes de gobernanza corporativa, que originaron los niveles de confianza más bajos desde 1981 en la economía del país y en sus funcionarios, según Richardson y Baril (2003).

Según Böckli en una cita hecha por Martin Hilb (2007), ante dicha crisis, ejercer la función de director en el país tendría la siguiente noción: "Muy importante puesto corporativo, con grandes responsabilidades legales para la compañía, gran riesgo para la reputación y responsabilidad financiera, pago exiguo, poco tiempo, apoyo o información para hacer

\footnotetext{
3. La IFC (Corporación Financiera Internacional) es la entidad financiera para el sector privado del Grupo Banco Mundial, y mantiene un Programa de Gobierno Corporativo con el financiamiento de la Secretaría de Estado para Asuntos Económicos del Gobierno Suizo (SECO), a través del cual busca trabajar con compañías para ayudar a implementar buenas estructuras y prácticas de gobierno corporativo que les permitan mitigar sus riesgos, protegerse contra la mala administración y atraer la inversión y el capital que impulsarán su crecimiento. Ello con la seguridad de que un buen gobierno corporativo fortalece a las empresas, las hace más eficientes y más responsables.
}

4. Ver nternational Finance Corporation, Navigating Through Crises. A Handbook for Boards. IFC, 2010, página 5.

5. Traducción hecha por el autor. 
el trabajo...y sin siquiera mucho reconocimiento hoy en día". En ese sentido, el desarrollo del GC se ha abierto paso ante las dificultades de gestión y, como hoy en día en nuestro país, ante las actuaciones poco éticas que afectan la imagen y con ello el rendimiento y eficiencia de una institución.

Entonces, el GC no es ajeno al cambio. Al contrario, debe asumirlo y adaptar sus componentes a todo aquello que influya directamente en la gestión eficiente de una empresa, para así generar el valor de actualidad y competitividad en la misma. Actualmente, uno de esos aspectos sobre los que necesariamente debe voltear a mirar el GC es a los temas de responsabilidad socio ambiental, convirtiéndose los componentes "ES\&G" (Environmental, Social \& Governance) en necesarios puntos de agenda en el directorio de las empresas; en algunas más que otras por su giro de negocio, pero de interés global y general, por el compromiso de velar por un mundo mejor y más sano.

Es así que el componente de responsabilidad corporativa debe tener necesariamente integrado a la ética y moral como ingrediente en el actuar de los miembros de una empresa, como ya hemos señalado en el apartado anterior, en la medida de una visión actual de compromiso de la empresa para con la sociedad y todos sus stakeholders en general, internos y externos.

El GC contiene componentes necesarios de medir e implementar en la buena dirección, planificación y marcha de la empresa. En esto, la IFC es un referente del GC para la banca de inversión. En su Programa de GC, ha establecido un sistema propio de concebir el mismo con principios y componentes necesarios para efectuar un correcto análisis al interior de las organizaciones y verificar su nivel de implementación y necesidades, que a continuación se resume:

\section{Principios del GC:}

1. Rendición de cuentas. - Resulta necesario que, en claro respeto a la línea jerárquica y naturaleza de la estructura de una organización, la administración de la misma acepte e implemente un sistema de rendición de cuentas al Directorio y, de la misma forma, el Directorio responda frente a los accionistas, que son quienes lo han colocado a la cabeza de la gestión estratégica de la institución.

2. Justicia.-Todos los accionistas tienen derechos, un mínimo establecido legalmente y otros que serán definidos por ellos mismos al momento de la constitución de la sociedad. Es necesario que estos derechos sean, en primer lugar, conocidos por todos, y protegidos a través de los documentos necesarios, desincentivando su afectación. Así mismo, justamente en virtud de estos derechos, es imperativo que todos los accionistas reciban un trato equitativo, incluso los minoritarios. Bajo este marco, en caso de la afectación directa de algunos de los derechos de los accionistas que le origine algún desmedro, debe dar lugar a la correspondiente reparación

3. Transparencia.- Debe asegurarse y luego regularse la oportuna y eficiente divulgación de la información de la empresa, en cantidad, naturaleza, plazo y forma.
Esta información puede incluir su situación fiscal, el desempeño de su gestión, la propiedad, el nivel de implementación mismo de los componentes del buen GC. Es necesario que se sepa identificar qué información estaría dentro de la divulgación que la empresa decida hacer y cuál dentro de la obligación de transparencia que el sistema normativo obliga, por encima de ese mínimo. Será voluntad de la sociedad el determinar la información a revelar.

4. Responsabilidad.- Como se ha señalado, la sociedad debe proteger los derechos de los accionistas, pero no sólo eso, sino que debe reconocerlos como tal y velar por su respeto. Así mismo y en virtud justamente de ellos, el GC busca que se fomente la permanente cooperación entre los accionistas y la gestión de la empresa para la creación de riqueza, empleo y sostenibilidad del negocio.

\section{Componentes del buen GC:}

1. Compromiso con el Buen GC.- Es necesario que exista la voluntad y asunción de responsabilidad de parte de los accionistas para dejar que el GC involucre la organización y decisiones de su empresa, de tal manera que se implemente un sistema integrado de respeto y apego por la gestión eficiente, transparente, ordenada; en busca de resultados positivos.

Este compromiso debe manifestarse en la coordinación que hacen los propietarios con las personas y puestos de gestión para decidir la implementación de un órgano de dirección con el que se busque la planificación y decisión estratégica de la compañía y, una vez constituido, dejar que él mismo sea quien realmente asuma la iniciativa en los temas de gobierno de la sociedad.

Ese necesario que este compromiso se haga de conocimiento no solamente por el staff de la compañía sino que se transmita a todos los stakeholders.

La implementación y gestión del GC requiere de que exista una estructura organizacional con puestos, personas y funciones claramente definidas; y que tanto éstas, como los principios y disposiciones propias de GC, sean plasmadas en políticas y procedimientos que los hagan imperativos, duraderos en el tiempo y pasibles de ser conocidos por todos.

La elaboración y programación de planeamientos estratégicos que articule objetivos, presupuestos, identificación de riesgos, responsabilidades, etc., es una manifestación clara del compromiso con el buen GC.

2. Toma de decisión y supervisión estratégica.- Los directores y en sí el colegiado del directorio, deben estar capacitados y preparados para la toma de decisiones eficientes para aportar en una gestión de éxito. Este rol de toma de decisiones es fundamental y determinante para procurar el éxito o caer en el fracaso. Es por ello que no debe escatimarse en preparar y buscar que el directorio llegue a decisiones correctas, aunque para ello sea necesario el contar con asesores externos que, elegidos por su especialidad, le den un valor agregado a la formación de la decisión que los directores deben tomar. 
Así mismo, para que haya una toma de decisiones eficiente, es necesario que el rol de los directores se encuentre plenamente definido a igual que los procesos propios del directorio.

El buen GC requiere que las decisiones se tomen luego de una deliberación alturada, que exista una estructura propia que regule el proceso de la decisión, debiendo constituir, si es necesario, una agenda y reuniones periódicas a través de comités especializados que cobijen a directores y gerentes, por ejemplo. De esta manera también se reduce el riesgo de la decisión a tomar.

3. Ambiente de control y procesos.- Una planificación y gestión eficientes requiere aminorar lo máximo posible los riesgos con los que cuenta una compañía, para que así la estructura de la organización y sus acciones estén preparadas ante su posible afectación. Quien conoce realmente sus falencias y peligros, sabrá como neutralizarlos. El objetivo primordial de una sociedad es generar utilidad. En esa búsqueda, es el manejo de sus recursos económicos un tema sensible, por lo que se debe buscar su seguimiento y control constante. En ese sentido, los flujos de caja y presupuestos deben ser parte de la discusión y acuerdos constantes de parte de la gestión y dirección de la empresa, de tal manera que las decisiones y planeamientos a los que se llegue, tengan en cuenta los límites del nivel de inversiones y gastos. Siempre será ideal en la estructura de un buen GC la existencia de una persona dedicada enteramente a las finanzas de la empresa.

En la búsqueda de esta eficiencia financiera y administrativa, el control interno y el externo deberán ser una de las prioridades de la empresa, de tal manera que haya siempre un control de los procesos, funciones y resultados de cada área, identificando siempre los riesgos y evitando así que las contingencias se vuelvan una afectación real. Los auditores deben siempre elegirse después de una evaluación a conciencia sobre el perfil que la empresa requiere y, sobretodo, deben ser personas ajenas al entorno de los accionistas y directores y sobre los que su elección ha sido totalmente transparente e independiente.

4. Transparencia y comunicación.- La transparencia y la comunicación tienen dos variantes, hacia el interior de la empresa y hacia el exterior, ésta hacia a los stakeholders de fuera. Debe identificarse qué información es la que debe ponerse en conocimiento de los accionistas y directores, como la de los estados financieros y qué información no financiera debe y puede hacerse de conocimiento, ya sea de todo el staff de la compañía, de las gerencias y/o jefaturas y de los stakeholders externos. Ello dependerá del tipo y naturaleza de dicha información y de sus posibles usos e impacto por parte de sus receptores. El uso de la página web corporativa debe optimizarse en busca del objetivo de la sociedad, como por ejemplo, tener siempre completa la información que un inversionista necesita, si ese es el objetivo. Es muy importante que los trabajadores conozcan cuáles son los límites de su actuación, funcional y personal, de tal manera que conozcan que su conducta tiene consecuencias.
5. Fundadores, accionistas y/o familia.- Es necesario que quede muy claro e identificados la personalidad y roles de quienes son propietarios, accionistas y/o familia dentro y fuera de la sociedad, de los administradores y gestores de la misma, definiendo los límites de actuación y la posible sucesión, de ser el caso.

Asimismo, componente importante del GC es la interacción en las sesiones de la Junta de Accionistas, aquellas en las cuales se aprobarán propuestas y decisiones preliminares tomadas por el directorio. Estas sesiones deben ser citadas con información relevante y agenda, con la debida anticipación a efectos de que los accionistas tengas un análisis hecho e ideas formadas en pro de una eficiente discusión e intercambio de ideas, para una toma de decisiones adecuada.

Como podemos ver, del Programa de GC del IFC, el GC será indispensable en la reputación corporativa en cuanto restablece una excelente oportunidad de análisis e implementación integral, horizontal y vertical de conductas y procesos que busquen el mejor rendimiento de una empresa; su mejor valoración; la eficiencia en sus resultados. Todo ello de la mano de un trato equitativo y justo, al interior, como al exterior, con derechos reconocidos y de pleno ejercicio; con niveles de supervisión que permitan la tranquilidad de los propietarios, del directorio y de la gestión misma en cuanto a la confianza en la ejecución de sus labores. La información será un elemento primordial para mostrar confianza y respeto al mercado y recibir lo mismo de parte de ellos, de tal manera que las empresas se hagan sostenibles y perdurables, en el único costo de hacer las cosas bien; manifestado ello, en una cultura de hacer bien las cosas, lo mejor posible, dentro de la legalidad y, sobretodo, del apego a la ética y una sana moral.

\section{UN DIRECTORIO REPUTADO}

\section{Señala Enrione (2012) que:}

El directorio y los directores pueden agregar valor a la empresa de variadas formas. Su prestigio personal, por ejemplo, puede ser un activo, una marca de calidad, que puede resultar importante para potenciales inversionistas. Sin embargo, cuando se trata de aportar hacia el interior de la empresa existe una forma esencial de hacerlo: generar valor a través del ejecutivo principal. (p. 45)

Y desde la óptica en que se enfoca el presente artículo, estamos de acuerdo en la postura de Enrione, en cuanto el tono desde arriba que maneja el directorio hacia la estructura vertical de la compañía, debe estar completamente comprometido con imprimir en la gestión y hacer del diario vivir de sus ejecutivos, el trabajo bien planificado, proyectado, estudiado, que se manifestará en órdenes y ejecución de una gestión transparente, eficiente y basada en conductas éticas y morales.

El tono desde arriba que maneja el directorio, debe imprimir en la estructura, procesos y sobretodo en las personas, una actuación ética, sincera, responsable, eficiente; debe orientar una conducta acorde a los valores morales que procuren una buena reputación. 
No obstante lo anterior, los miembros del directorio puede ser duchos en diferentes especialidades y no necesariamente abarcar todas las áreas de desarrollo que necesita una gestión eficiente; y es precisamente por eso que Enrione, en el mismo artículo citado, propone el desarrollo de cuatro objetivos o responsabilidades, en las que los miembros del directorio pueden aportar un valor enorme para la empresa, que serán una línea de acción y decisión propia, de carácter indelegable a la gestión o administración propiamente dicha, y requerirán de su dedicación, esfuerzo y energía. Los cuatro registros son:

1. Dirigir al que dirige.- Tarea fundamental es la de la elección del ejecutivo principal correcto y la preocupación porque él mismo tenga los incentivos que le mantengan motivado a perseguir y lograr los objetivos de los accionistas, procurando afrontar los riesgos razonables y con vocación de permanencia. El directorio debe fijar y sobretodo manifestar de manera clara los objetivos que debe procurar el gerente y las líneas de acción generales para ser alcanzados. El directorio debe ahorrarle la energía al gerente de establecer criterios generales, estándares, prioridades y de esta manera, hacerle responsable de objetivos concretos en cada aspecto, como, por ejemplo, el desempeño financiero, el clima laboral, la calidad de su equipo gerencial o la propia relación con el directorio. Como señala Enrione, los directores pueden entonces ser los ojos y oídos de la administración hacia fuera de la empresa y ayudarle a enriquecer su análisis y mejorar el proceso de toma de decisiones. Y, adicionalmente, ser aliados de la gestión para apertura de relaciones a las que no puede tener acceso.

2. Elegir la estrategia.- Será el Directorio quien tenga la responsabilidad de plasmar el interés de los accionistas en una visión y en una estrategia que permitan alcanzar. No se habla de estrategia cuando lo que existe son discursos rimbombantes respecto de la visión/misión de la compañía y compromisos de respeto a conceptos inmateriales o de responsabilidad para con la sociedad, el medio ambiente y los stakeholders. La estrategia requiere de un comportamiento serio y de asumir la responsabilidad de guiar los resultados positivos de la sociedad, identificando correctamente el presente, la situación, las fortalezas y debilidades de la organización, para en base a ello, establecer una guía de actuación, las políticas y planes necesarios a ejecutar, siempre enfocados en la ejecución de los mismos, a efectos que queden en un simple manual de buenas acciones. Pero, sobre todo, dar los pasos necesarios, pasar a la acción, medida, enfocada, proyectada y ahora con la dirección necesaria para llegar a buen puerto en relación con los objetivos organizacionales.

3. Arbitrar intereses.- Son varios los aspectos complejos que se presentan en una sociedad respecto de los cuales el directorio debe mediar de manera justa y siempre persiguiendo los intereses de la organización por sobre los intereses individuales o grupales que existen. Uno de esos intereses particulares es el de los accionistas como propietarios y a la vez de cada accionista por sí mismo, razón por la cual las decisiones que el directorio tome deben medir el impacto en el enriquecimiento o empoderamiento de los accionistas sobre otros, buscando siempre el equilibrio y la armonía. Asímismo, debe arbitrar sobre las acciones a tomar por parte de la línea ejecutiva para el cumplimiento de las metas en la aplicación de sus estrategias. También sobre la relación entre y con los stakeholders, base esencial para el buen desempeño y obtención de resultados.

4. En cada empresa con resultados exitosos existen activos que no necesariamente se reflejan en los documentos de resultado o en los estados financieros, pero que sin duda marcan un propio estilo y buena forma de hacer las cosas. Es responsabilidad de los directores identificarlas y hacer de ella "políticas", "procesos" y protegerla para que siga siendo un respaldo importante en la consecución de los objetivos empresariales

Muchos de estos elementos componen la real visión, los valores y los principios y son los que el directorio debe procurar sembrar en todos los sistemas que busquen la mejora continua del valor humano y de los procesos. Un documento importante para esto es el Código de Ética de la organización.

Un activo que las últimas décadas ha adquirido mayor importancia y con justa razón en cuanto es muchas veces este activo el que marca el espíritu y la reputación corporativo, es la marca; y su evaluación es ya un ejercicio importante en la valorización de las empresas. A continuación, se muestra el ranking de Interbrand a 2016 de las marcas más valiosas del mundo, en miles de millones de dólares:

\section{Tabla 1. Ranking de Marcas 2016}

\begin{tabular}{|c|c|c|c|}
\hline Posición & Marca & Sector & $\begin{array}{c}\text { Valor de } \\
\text { marca (en } \\
\mathbf{5 m}\end{array}$ \\
\hline 01 & Apple & Tecnología & 178,119 \\
\hline 02 & Google & Tecnología & 133,252 \\
\hline 03 & Coca Cola & Bebidas & 73,102 \\
\hline 04 & Microsoft & Tecnología & 72,795 \\
\hline 05 & Toyota & Automotriz & 53,580 \\
\hline
\end{tabular}

Fuente: Adaptado de https://www.interbrand.com

Otro aspecto que es fundamental en el directorio para marcar la ruta de la buena gestión y por ende de la buena reputación de la empresa, es su responsabilidad ética, esa cuya ausencia marcó la ola de fracasos empresariales.

Álvaro Pezoa (2012) ha planteado, acertadamente creo, diez responsabilidades éticas que los directores deben guardar para darle e incrementar valor reputacional a la organización, pues se verán reflejadas en estrategias limpias y acciones buenas y eficientes. A continuación, las presento textualmente, a partir de la página 91 del original:

1. Aumentar el valor para los accionistas.- Es la primera y más obvia responsabilidad que enfrentan los directores (...). Se traduce en velar por la maximización de la rentabilidad dentro de lo posible y de forma 
legítima, esto es, moralmente recta. Implica, asimismo, prever y cuidar que el aumento de valor económico se armonice en su dimensión temporal: es decir, se dé tanto en el corto como en el largo plazo. Conlleva, por lo mismo, el deber de decidir qué rentabilidad privilegiar si la obtención de ambas se presentase como antagónica (normalmente, es preferible optar por el largo plazo y la continuidad del negocio).

2. Incrementar el valor o beneficio para todos los grupos de interés (stakeholders) relevantes.- De acuerdo a una concepción integral de lo que es la empresa, su actividad y sus derechos y deberes con diversas esferas de la vida social, la respuesta que se espera de los directores no dice relación únicamente con los accionistas, sino que incluye a todos aquellos grupos de interés (stakeholders) que se vinculan de modo medianamente relevante con la empresa. Entre ellos, cabe considerar a: los trabajadores y sus respectivas familias, los clientes actuales y potenciales, los proveedores, las comunidades donde la compañía opera o produce, todo aquel grupo o comunidad que pueda ser dañado (externalidades negativas) por su quehacer, la sociedad, etc. Y, por supuesto, corresponden deudas de protección y preservación del entorno ecológico, las que, en último extremo, constituyen un deber con la humanidad en sus generaciones presentes y futuras.

3. Preservar algunos equilibrios básicos.- (...) Entre esos balances críticos es posible mencionar: i) Aquel que ha de darse entre la eficacia y la eficiencia con atenerse, al mismo tiempo, a conductas éticas, tanto en la determinación de fines como en el uso de medios[;] ii) En conexión con el punto anterior, la necesaria consecución de beneficios económicos con el aporte al bien de los stakeholders y al bien común social[;] iii) La ya mencionada armonización entre los objetivos de corto y largo plazo, en particular la obtención de utilidad/rentabilidad en el primero versus la imprescindible sustentabilidad en el segundo. Es decir, la conciliación del éxito en ambos periodos de tiempo.

4. Cultura y principios.- En su calidad de órgano superior de gobierno de la empresa, el directorio tiene una clarísima obligación de velar por el desarrollo, fortalecimiento y permanencia de los elementos constitutivos esenciales de la cultura de la empresa correspondiente. Más allá de quién o quiénes sean los encargados de "gestionar" en el quehacer cotidiano la cultura empresarial, son los directores quienes han de tener la última palabra. Obviamente, esto implica incorporar en la "agenda del directorio" la revisión y el tratamiento de esta dimensión crucial de la organización que incluye, como uno de sus factores fundamentales, la definición de los principios éticos más destacados que se desea vivir y respetar en su entera actividad (...)

5. Incentivos para la alta gerencia.- Capítulo especial requieren también los incentivos económicos que se establecen para la alta gerencia, no únicamente para el gerente general. Por sus repercusiones ésta ha llegado a ser una responsabilidad grave para los directores. La historia reciente, tanto en el mundo como en Chile, es fructífera en buenos y malos ejemplos de prácticas empresariales en este rubro. Puede sostenerse que habitualmente los "incentivos funcionan", es decir, mueven a las personas hacia la consecución de los fines que motivan a perseguir, con las secuelas positivas y negativas que ello puede siempre comportar. La crisis financiera mundial reciente (2008-2009), puso en evidencia de forma expresiva cómo los incentivos colaboraron a que numerosos CEO y otros altos directivos de empresas transgredieran los límites de la prudencia y, en varias oportunidades derechamente los de la ética, con tal de alcanzar los objetivos que, en la práctica, motivaban los incentivos económicos que les habían sido otorgados o habían convenido con los boards de sus respectivas corporaciones. Es interesante consignar aquí que todo proceso de determinación de incentivos posee en sí mismo una dimensión moral, puesto que estos buscan encauzar y modificar conductas libres, encaminándolas a la búsqueda de ciertos fines (en detrimento de otros alternativos) y, por lo tanto, a la elección de los medios que permitan alcanzar esos fines.

6. Prevenir y resolver conflictos de intereses.- (...) recae en el directorio la responsabilidad de tutelar por la adecuada prevención de los mismos y, en caso de ocurrencia efectiva, por la existencia de mecanismos de detección, comunicación y de correcta resolución de ellos. Partiendo, por supuesto, por aquellos conflictos de intereses potenciales o actuales que conciernen al directorio y a sus miembros. (...) siempre resulta recomendable adelantarse, en la medida de lo posible, detectando los conflictos de intereses potenciales y generando mecanismos de prevención para ellos (...). Respecto a este ítem es preferible un grado de celo profesional que procure eliminar -o mitigar en todos los ámbitos de la organización, consideradas tanto sus relaciones internas como externas, incluso hasta las sospechas infundadas de posibles conflictos de intereses.

7. Obtención y uso de información.- Uno de los campos más complejos que encaran las organizaciones en la actualidad es el relativo a la correcta obtención y uso de la información. Se trata, por cierto, de una dificultad cada vez más aguda en todos los contextos sociales, habida cuenta de que la generación, disposición, traslación y utilización de la información ha sido radicalmente modificada con las nuevas tecnologías. La empresa no es excepción. Cautelar los derechos de posesión y uso de la información pertinente ha llegado a ser una tarea de máxima importancia y, precisamente por su trascendencia, debe ser incorporada en el catálogo de las responsabilidades éticas exigibles al directorio (...) Particular acento se precisa respecto al uso de información reservada, confidencial y privilegiada, partiendo como es obvio por el propio funcionamiento del directorio Por otra parte, propender a la máxima transparencia posible en las comunicaciones internas y externas de la empresa parece ser otra de las aristas que deben promover y tutelar los directorios (...)

8. Responsabilidad social empresarial (RSE).- La RSE es una dimensión connatural a la vida de la empresa. Es así, según se desprende de una adecuada comprensión del orden social, donde ella es lo que se denomina un 
organismo social intermedio (entre la familia, célula básica de la sociedad, y la sociedad política) y, por tal razón, posee derechos y deberes respecto a los distintos estamentos de la sociedad con quienes se relaciona directa o indirectamente (...) Razón que hace patentemente manifiesto que el deber del directorio de ser el máximo responsable de la RSE, al menos respecto a sus principios, enfoque estratégico y al control de su ejecución efectiva, posee una profunda connotación ética.

9. Responsabilidad última.- Una serie de tareas cruciales en el devenir de una empresa de negocios ha de ser cautelada/asegurada, promovida y controlada por sus directorios. Aunque no sean ellos quienes deban asumir el peso del esfuerzo por hacerlos realidad, sí son finalmente parte de sus deberes insoslayables en su calidad de órgano superior del gobierno empresarial $\mathrm{y}$, en tal sentido, les asiste una responsabilidad última sobre las mismas. Entre estas realidades, destacan: i) La estrategia corporativa, ii) Los riesgos del negocio (financieros, crediticios, operativos, político-sociales, macroeconómicos, delitos y lavado de dinero, climáticos y catástrofes naturales, medioambientales, etcétera) iii) El control de gestión, (iv) La selección, evaluación y control de la alta gerencia, en especial del gerente general. Es evidente a este respecto que el directorio debería conocer personalmente a la plana ejecutiva mayor, v) Las políticas y prácticas respecto a la dotación de personas que conforman la organización, incluyendo aquellas que guardan relación con las familias de las mismas. Específicamente, cabe destacar en este ámbito, la toma de conocimiento y seguimiento de las encuestas de clima organizacional, de las prácticas pro conciliación entre el trabajo y la vida familiar, y de las políticas de retribución económica a los colaboradores de la empresa, vi) Las diversas auditorías y actividades contraloras que se realicen a la compañía. Al respecto, el directorio debe tener siempre cauces de comunicación directos con los auditores y contralores. Según muestra la experiencia, conviene utilizarlos con prudencial frecuencia y, en cualquier caso, toda vez que se estime necesario por razones puntuales de importancia.

10. Realizar a conciencia la propia tarea.- En cierto sentido podría ser considerada la primera responsabilidad ética del director, pues todas las restantes requieren de ésta o se sustentan en ella (...) Cuestiones como: el número de directorios en que son miembros los directores; el tiempo que pueden dedicar a la preparación de las reuniones y a mantenerse adecuadamente al tanto de la marcha de la empresa, más allá del tiempo dedicado a asistir a las sesiones ordinarias y extraordinarias; la preparación profesional para ejercer bien las tareas de director; el tipo y oportunidad de la información solicitada a la gerencia general con antelación a las sesiones de directorio; la calidad del debate que se establece durante las mismas; la evaluación (o autoevaluación) y las medidas de corrección y mejora en el funcionamiento del directorio; y un largo etcétera, pueden hacer que el trabajo de un director, y el desempeño de los directorios, estén o no a la altura de las necesidades que exige tan alto órgano de gobierno empresarial. Abordar estas y otras cuestiones con seriedad representa una obligación moral de indudable exigencia para todas y cada una de las personas que ejercen tareas directivas de este orden.

La labor de los miembros del directorio no es solamente de imagen (a veces ni siquiera eso); de transmitir seguridad a los stakeholders externos; de validar decisiones ya tomadas por los propietarios y la gerencia. Si realmente existe conciencia del deber moral que les asiste y la responsabilidad no solamente para sus accionistas, sino para todos lo que, directa o indirectamente, dependan de la empresa, para con su propia responsabilidad y su propia tranquilidad y respeto a sí mismos, sus capacidades, su formación, sus valores, se habrá comprendido el compromiso por un actuar ético, de dedicación, de búsqueda de la eficiencia y de la excelencia.

\section{NECESIDAD DE CONTROL DE RESPONSABILIDADES Y CONTROL DE RIESGOS}

En todo negocio y actividad económica en general, van a haber riesgos, de diferente tipo y efecto. El reto está en identificarlos, conocerlos y reconocerlos, de una manera completa y profunda a razón de realizar una evaluación costo-beneficio y determinar si, a pesar del mismo y su influencia y posibles impactos, sigue siendo rentable generar la actividad. Decidido ello en positivo, surge la necesidad de gestionar correctamente los riesgos para que esa evaluación resulte real al momento de la ejecución de las acciones en pro de la generación de utilidad económica y pueda aminorarse los resultados negativos en la mayor medida posible.

Es fundamental atacar el riesgo desde su origen, habiendo conocido su propia naturaleza. En ese sentido, el esperar a que el riesgo genere consecuencias para recién ahí atenderlas resulta muy peligroso en su impacto, pudiendo ser determinante en la buena marcha de la empresa y en el tiempo en que la misma pueda reponerse. Sin embargo, conociendo su naturaleza y atacando su origen, surge la oportunidad de poder desaparecerlo por completo o mermar sus efectos negativos al máximo, con mayor probabilidad y porcentaje de éxito.

Al hablar de la naturaleza de los riesgos, el más común que las empresas identifican sin mayor profundidad de análisis y por su impacto muchas veces permanente y muy a corto plazo, es el financiero. Sin embargo, existen otros relacionados más con la planificación estratégica y de largo plazo, a saber:

Figura 1. Riesgos de largo plazo relacionados con la planificación estratégica

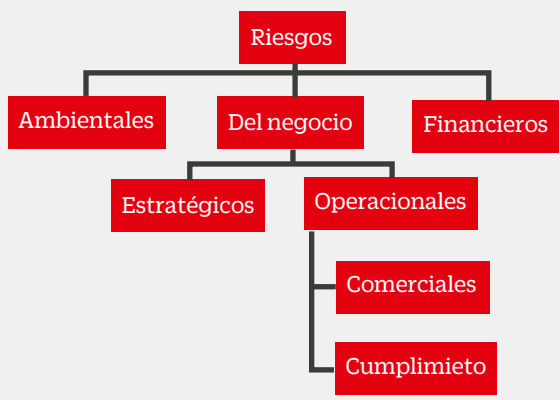


Al respecto, señala Díaz et al. (2007):

Los riesgos del negocio para una compañía son aquellos que surgen por la naturaleza de éste y sus operaciones. A su vez estos riesgos se dividen en estratégicos, que surgen de las decisiones y objetivos estratégicos de largo plazo que adopta una organización, y operacionales, más de corto plazo. Dentro de los operacionales se distinguen los comerciales, aquellos que surgen de variaciones en el corto plazo de las condiciones del negocio, tales como debilitamiento de la venta, un aumento inesperado en remuneraciones, etcétera; $y$ los de cumplimiento (compliance), que se refieren a la deficiente implementación de políticas, procesos y procedimientos en la organización. Desde el punto de vista de la naturaleza de los riesgos, los del negocio son usualmente de doble vía y especulativos. Entre los de doble vía (aquellos en que el resultado es distinto, mejor o peor al esperado) se incluyen riesgo de producto, macroeconómico y tecnológico. Entre los riesgos del negocio especulativos se encuentra el riesgo estratégico. También entre los riesgos del negocio hay riesgos puros, por ejemplo riesgos de propiedad y accidentes. Los riesgos distintos a los del negocio incluyen financieros y de eventos externos. Entre los financieros encontramos de crédito, de tipo de cambio, de tasa de interés, de liquidez, de mercado, precio de commodities, de apalancamiento, etcétera. Con respecto a riesgos de eventos externos, se pueden catalogar en riesgos de litigio o legales, de continuidad del negocio, regulatorio y político. (p. 210)

Haré un paréntesis a la exposición teórica para ver cómo se está tratando el riesgo y la importancia que se le da en documentos normativos de autoridades y organizaciones en el Perú y de otros que son de impacto para el país, así como algunos datos numéricos.

Para 2017, la Superintendencia del Mercado de Valores hizo un informe sobre el cumplimiento del Código de Buen Gobierno Corporativo para las Sociedades Peruanas ${ }^{6}$, empresas emisoras. Aquí algunos datos numéricos, teniendo en cuenta que fueron 216 empresas las que atendieron el cuestionario, cuyo Pilar IV está referido al Riesgo y Cumplimiento:

1. ¿El Directorio aprueba una política de gestión integral de riesgos de acuerdo con su tamaño y complejidad, promoviendo una cultura de gestión de riesgos al interior de la sociedad, desde el Directorio y la Alta Gerencia hasta los propios colaboradores? 67 empresas respondieron que no

2. ¿La política de gestión integral de riesgos alcanza a todas las sociedades integrantes del grupo y permite una visión global de los riesgos críticos? 92 empresas respondieron que no, es decir, existirían 25 empresas que forman parte de un grupo empresarial que si bien tiene una política de riesgos, no la aplican a todas las empresas integrantes del grupo.

6. Ver http://www.smv.gob.pe/Frm_RptGobiernoCorpAll?data=D2 6422E1700E88ABE1959663E80941AA2B336827F2
3. ¿La sociedad cuenta con un sistema de control interno y externo, cuya eficacia e idoneidad supervisa el Directorio de la Sociedad? 45 empresas respondieron que no.

4. ¿El auditor interno realiza labores de auditoría en forma exclusiva, cuenta con autonomía, experiencia y especialización en los temas bajo su evaluación, e independencia para el seguimiento y la evaluación de la eficacia del sistema de gestión de riesgos? 56 empresas respondieron que no.

5. ¿La sociedad mantiene una política de renovación de su auditor independiente o de su sociedad de auditoría? 92 empresas respondieron que no.

6. En caso que dicha política establezca plazos mayores de renovación de la sociedad de auditoría ¿el equipo de trabajo de la sociedad de auditoría rota como máximo cada cinco (5) años? 100 empresas respondieron que no.

Como podemos ver, no existe una total identificación con la importancia y la necesidad de ejecutar una completa y eficiente gestión de los riesgos al interior de la organización. Muchas veces esto puede deberse a la falta de recursos para ello; otras, simplemente porque le dan más importancias al riesgo de modificar la forma tradicional en que se ha venido gestionando la empresa, con resultados buenos sin necesidad de mayor gasto, mayor complejidad ni de ser incisivos en el control. En ambos casos, la expectativa de resultados nefastos para la empresa es la misma. Hemos visto en las crisis de EE.UU., en la del Perú y de América Latina en general que, el papel aguantan todo. La buena imagen de tener un completo sistema de gobierno corporativo es moda. Sin embargo cuando ello no responde a una ejecución real en la toma de decisiones y en la gestión de la empresa, y los riesgos se manifiestan, los resultados pueden ser nefastos. La sola crisis de Odebrecht, por ejemplo, a febrero de 2018 tenía a 169 proveedores, de sus 450, quebrados y se estima que a marzo sería el 80\% en esa situación.

Del documento, “Directrices de la OCDE sobre el Gobierno Corporativo de «las Empresas Públicas"7, organismo al que el Perú pretende ingresar, saltan muchas ideas clave relacionadas con la gestión de riesgos. Revisemos algunas a continuación:

1. Las empresas públicas deberían revelar la información importante sobre todos los temas descritos en los Principios de la OCDE sobre Gobierno Corporativo y, además, centrarse en las áreas de interés especial para el Estado como propietario y el público en general.

2. Siempre que sea necesario, los directorios de las empresas públicas deberían constituir comités especializados para ayudar al pleno del directorio en el desempeño de sus funciones, especialmente en lo que se refiere a la auditoría, gestión del riesgo y remuneraciones.

3. Como sucede en las grandes empresas listadas en bolsa de valores, las empresas públicas de gran tamaño necesitan crear un sistema de auditoría

7. Ver https://www.oecd.org/daf/ca/corporategovernanceofstateownedenterprises/48632643.pdf 
interna. "La auditoría interna constituye una actividad de consultoría que ofrece una garantía objetiva e independiente, diseñada para aumentar el valor y mejorar las actividades de una organización. Ayuda a la organización a alcanzar sus objetivos mediante la contribución de un enfoque sistemático y disciplinado para evaluar y mejorar la efectividad de los procesos de gestión del riesgo, control y gobierno corporativo.

4. Se pueden presentar graves dificultades cuando las empresas públicas emprenden estrategias ambiciosas sin haber claramente identificado, evaluado o informado debidamente sobre los riesgos asociados a las mismas.

5. Con el fin de subrayar las responsabilidades del directorio, habría que facilitar un informe de gestión de los directores junto con el balance anual y remitirlo a los auditores externos. El informe de gestión de los directores debería proporcionar información y observaciones sobre la organización, desempeño financiero, factores de riesgo importantes, acontecimientos significativos, relaciones con partes interesadas, y efectos de las instrucciones de la entidad coordinadora o propietaria.

6. Con el fin de llevar a cabo su papel, los directorios de las empresas públicas deberían activamente i) formular, supervisar y revisar la estrategia corporativa, enmarcados en los objetivos corporativos generales; $\mathrm{y}$ ii) establecer indicadores de desempeño adecuados e identificar riesgos clave (...)

Totalmente viable aplicar estas disposiciones para las empresas netamente privadas.

Por su parte, en el Código de Buen Gobierno Corporativo para las Sociedades Peruanas, en su Principio 25 sobre el Riesgo y Cumplimiento y el entorno del sistema de gestión de riesgos, se señala que es el Directorio quien debe aprobar una política de gestión integral de riesgos, esto en función del tamaño y lo complejo de la estructura y funcionamiento de la organización. Así mismo, define roles, responsabilidades y promueve a toda la verticalidad de la estructura; una cultura de gestión del riesgo. Corresponde, a su vez, a la gerencia general, supervisar periódicamente los riesgos, su impacto, nivel de desarrollo, para mantener informado al directorio al respecto. Es el directorio el responsable de la existencia de un sistema de control y seguimiento de riesgos y para ello es esencial que se constituya un comité de auditoría

El manejar en forma eficiente los riesgos requiere de muchas acciones y definición de roles de manera continua y la implementación de todo un sistema. Existen diversos modelos para ellos, pero el más difundido es el llamado Enterprise Risk Management (ERM) basado en la metodología $\operatorname{COSO}^{8} 9$ (Ver Figura 2):

8. COSO, Committee of Sponsoring Organizations of the Treadway Commission; 2004. Enterprise Risk Management Integrated Framework.

9. Gráfica tomada de Díaz Molina, Iván. “Directorio y riesgo, una relación necesaria”. En: Enrione, A. Directorio y Gobierno Corporativo. ESE Businees School, Universidad de Los Andes, 2012, pag. 213
Figura 2. Modelo Enterprise Risk Management
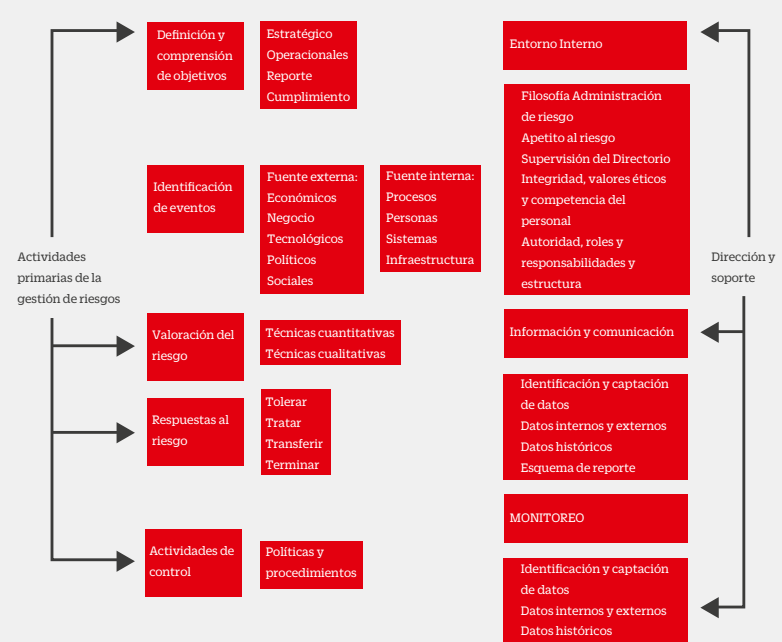

A saber del tema del presente artículo, existe un riesgo que es importante tener en cuenta: el riesgo reputacional. De lo anteriormente dicho en el presente acápite, si este riesgo es manejado incorrectamente se tendrá un resultado negativo en la reputación empresarial.

Ha señalado Tomás Garicano (2011) en su trabajo “Buen Gobierno y Reputación Corporativa" para el IE Business School, que:

Tradicionalmente, se ha considerado el riesgo de reputación como la posibilidad de que un acontecimiento dañase la Reputación Corporativa de la empresa. Aunque la Reputación Corporativa no se pueda medir financieramente con precisión, la posibilidad de que el valor de la empresa se pueda ver reducido representa un riesgo clave del negocio. Podemos definir el Riesgo Reputacional como el impacto, favorable o desfavorable, que un determinado evento o suceso puede causar en la reputación de la empresa. (p. 102)

Este tipo de riesgo se va a presentar cuando la empresa genera un impacto negativo en la imagen que los stakeholders se formen de ella, ahí se relaciona el concepto mismo de reputación corporativa que hemos tratado al inicio de este artículo. Según ello, estos stakeholders serán los que marcarán, al ser hostiles, el destino y nivel de impacto del riesgo materializado, en la reputación corporativa. A manera de ejemplo, podemos recordar dos escándalos de crisis globales:

1. Enron, cuya crisis generó un impacto negativo en su auditora, Arthur Andersen, una de las más grandes a nivel mundial, que tuvo en la persona de dos de sus funcionarios a quienes avalaron el fraude en papeles de la internacional de energía. Pues la caída de Arthur Andersen se debió a que sus clientes más grandes decidieron dejar de serlo y en pocos días ya no tenía respaldo.

2. El fraude en el sistema de emisiones de los autos de Volkswagen y su mal manejo de este riesgo de la crisis misma, generó impactos que fueron en alguna medida marcados por sus stakeholders, la pérdida de 
confianza y respaldo de los mismos, VW sufrió un 35\% de descenso en su cotización en Bolsa en la primera semana de conocerse el evento. Así mismo, 6,500 millones de euros fue la provisión realizada por la compañía para gestionar la crisis; 51,000 millones de euros fue lo perdido en bolsa en el sector del automóvil durante los primeros días de la crisis.

Lo más entendido es que los riesgos reputacionales son consecuencia misma de la crisis en los riesgos operacionales o estratégicos presentes en las empresas. Sin embargo, existen riesgos reputacionales puros y son aquellos que no se producen como algo derivado necesariamente de los primeros. Por ejemplo, señala Garicano (2011) en su trabajo citado arriba: "la transparencia, la confianza, el acceso a las tecnologías de la información y de las comunicaciones (ICT), el desarrollo económico, la privacidad y la seguridad, la protección del inversor, el cambio climático o el buen gobierno corporativo" ( $p$. 103). Sin embargo, es necesario dejar en claro que muchos expertos no reconocen a los riesgos reputacionales como algo propio y con naturaleza propia, sino como derivados, como hemos señalado de otros riesgos más pasibles de materialización y medición objetiva.

Nos queda claro que la gestión de los riesgos es importante para estar preparados ante cualquier contingencia, pues depende del impacto de la materialización de la misma; y el nivel de prevención y preparación serán sus efectos más o menos perjudiciales para la organización. Su respuesta a ello marcará la necesidad de ajustes mínimos, reorganización o el inicio de su proceso de liquidación.

\section{CONCLUSIONES}

La reputación corporativa es un elemento de vital importancia hoy en día para las empresas y aun cuando su cuantificación económica global es muy complicada, tiene un valor propio en el sentido mismo de constituir un ingrediente de mejor o peor imagen en los stakeholders, quienes sí pueden darle un impacto numérico negativo a través de la disminución de la confianza y respaldo.

Ha quedado clara la necesidad y urgencia del manejo eficiente de los diferentes riesgos que afronta una organización. Ello, desde su identificación, aceptación e inclusión en la agenda del directorio; y en su propio manejo, a través de políticas imperativas, drásticas. Es fundamental una identificación con el problema de toda la estructura vertical y un compromiso conjuntos de mejorar el control y buscar resultados favorables. Debe definirse una cultura organizacional del riesgo a través de un sistema integral eficiente.

En la línea de los expresado en el párrafo anterior, resulta muy importante en el manejo de los riesgos organizacionales, el riesgo reputacional, pues si bien puede ser poco reconocido como riesgo propiamente dicho y no derivado, sí tiene una valoración económica negativa en la pérdida de la confianza, base para perder valor económico. Las empresas están cada vez más involucradas en implementar un sistema propio basado en reconocer la existencia de la Reputación Corporativa y el Riesgo Reputacional, otorgándoles un valor real y entendiendo que sí tienen impactos materializables y graves.

Realmente la puesta en marcha de un gobierno corporativo, en sus Principios, en sus componentes propios, en su naturaleza, establecen las bases organizacionales para generar un mayor valor y resultados financieros y no financieros mejores a una organización, así como por ejemplo un mejor acceso a créditos o el otorgamiento de confianza suficiente a nuevos inversionistas, toda vez que su implementación otorga una imagen de orden, estabilidad, compromiso de permanencia en el tiempo y un bajo riesgo de actuaciones ilegales o inmorales. Así, es el directorio, como órgano fundamental el que asume en un sistema de buen gobierno corporativo, el que asume la tarea de implementar un sistema eficiente de gestión de riesgos y por intermedio de esta ocuparse también de la buena reputación corporativa. Y ésta, por su parte, necesariamente tiene como uno de sus ingredientes el buen gobierno corporativo.

Si bien, como hemos visto en las estadísticas del cumplimiento del Código de Buen Gobierno Corporativo de 216 empresas emisoras, existe un compromiso acaso poco masificado de la gestión integral de los riesgos y, con ello un poco de aceptación o, mejor dicho un poco de relacionamiento de ello con el concepto de buena reputación corporativa, la tendencia, forzada o no por las crisis existentes, es a que se les relacione más directamente. Ello lo complemento con dos ejemplos. Estas son dos crisis que han tenido resultados negativos en empresas directamente vinculadas con la razón de esas crisis, pero que a la vez han arrastrado a empresas que no han tenido ninguna injerencia directa en dicho resultados: es el caso de Agrobanco y el de Odebrecht. En estos dos ejemplos de crisis por malas prácticas de gobierno corporativo, han "pagado" muy caro empresas que no han tenido que ver con las razones de sus malos manejos y efectos negativos, pero la reputación corporativa de estas dos organizaciones ha sido de tal impacto que les ha tocado directamente a su propia reputación corporativa. Claramente, la mayoría de ellas no había previsto un buen manejo de este tipo de riesgo reputacional.

Finalmente, en relación a lo mencionado arriba podemos decir con convencimiento y júbilo que estamos en el camino correcto para que el riesgo reputacional sea entendido, asumido y tratado como un riesgo de impacto, una administración de mucho valor; y en la importancia no sólo en la reputación corporativa de la empresa, sino en la necesidad, tanto de un manejo ético, como de una gestión con rostro humano y responsabilidad social en todas las organizaciones. 


\section{REFERENCIAS}

Costa, J. (1977). La imagen de la empresa. Métodos de comunicación integral. Madrid, España: Biblioteca de la Comunicación del Centro de Investigación y Aplicaciones de la Comunicación/Ibérico Europea de Ediciones.

Díaz, M., Gutiérrez, P. \& Vásquez, J. (2007). Algunas consideraciones sobre la ética en el mercado. Pecvnia: Revista de la Facultad de Ciencias Económicas y Empresariales, Universidad de León, 5, 9-51. doi: 10.18002/pec.vOi5.710

Enrione, A. (2012). Directorio y Gobierno Corporativo Santiago de Chile, Chile: Editorial ESE Business School.

Freeman, R., E. (2010). Strategic management: A stakeholder approach. New York, NY: Cambridge University Press.

Garicano, T. (2011). El Gobierno Corporativo y la Reputación Corporativa. Madrid, España: Centro de Gobierno Corporativo.

Hilb, M. (2007). Gobierno Corporativo. CABA, Argentina: Temas Grupo Editorial SRL .

Pezoa, A. (2012). La responsabilidad ética del director de empresas. En A. Enrione (Ed.), Directorio y gobierno corporativo: El desafío de agregar valor en forma sostenida (cap. 6). Santiago de Chile, Chile: Editorial ESE Business School.

Richardson, R. C., \& Baril, C. P. (2003). Can your audit committee withstand the market's scrutiny of independence? (audit comittees). Financial Executive, 19(1), 35-39. Obtenido en http://go.galegroup.com/ps/ anonymous?id=GALE\%7CA96952541\&sid=googleScho lar\&v=2.1\&it=r\&linkaccess=abs\&issn=08954186\&p=AO $\mathrm{NE} \& \mathrm{SW}=\mathrm{w}$

Villafañe, J. (2002). Imagen positiva: Gestión estratégica de la imagen de las empresas. Madrid, España: Pirámide.

Wartick, S. (2002). Measuring corporate reputation:

Definition and data. Business \& Society, 41(4), 371-392.

doi: $10.1177 / 0007650302238774$ 